TESTIMONIO 
Rol de Anfolchi en la práctica de la Cueca

Role of Anfolchi in the practice of the Cueca

Pp. 191 a 197

\title{
ROL DE ANFOLCHI EN LA PRÁCTICA DE LA CUECA
}

\author{
ROLE OF ANFOLCHI IN THE PRACTICE OF THE CUECA
}

\author{
María Gloria Cancino Gatica \\ Luisa Pinto Celis \\ ANFOLCHI \\ Chile
}

A través de este testimonio, presentamos brevemente una historia de nuestra organización, en relación especial con el Decreto № 23 de 1979 y sus efectos sobre el cultivo de la cueca y el folklore.

La Asociación Nacional del Folklore de Chile, ANFOLCHI, es un organismo cultural autónomo, sin fines de lucro, que rescata, defiende y promueve los valores de la cultura tradicional y sus expresiones. Agrupa a conjuntos folklóricos, artesanos, cultores, músicos, investigadores y a personas interesadas en el rescate, defensa y promoción de nuestra cultura popular. Sus objetivos se cumplen a través de actividades de difusión a la comunidad, realizando encuentros, cursos y capacitación dirigidos a directores e integrantes de grupos de proyección folklórica. Las capacitaciones, por ejemplo, se concentran en reflexionar sobre la importancia del folklore, su investigación y estrategias de proyección de la riqueza folklórica -sean los casos, la guitarra campesina, educación de la voz, técnicas corporales para las danzas tradicionales, proyección escénica y teatral, entre otros-, divulgación de experiencias y valoración integral de las distintas manifestaciones del folklore, a fin de asegurar la mística interna y el compromiso permanente con nuestros cultores naturales.

$\mathrm{Su}$ actual directorio está compuesto por Carlos Martínez Miranda (Presidente), Bernardo Chávez Chávez (Vicepresidente), María Gloria Cancino Gatica (Secretaria General) y Silvia Gutiérrez Villagrán (Tesorera).

Nuestra organización nació el 19 de mayo de 1980 como Asociación Metropolitana de Folklore de Chile - AMFOLCHI, logrando incorporar a 
treinta agentes activos. Durante sus primeros años, los miembros participaron activamente en reuniones que dotaron de un cuerpo administrativo y políticotécnico a la organización, como encuentros metropolitanos, seminarios y capacitaciones, en distintas áreas de interés.

En abril de 1991 se celebró el Primer Congreso Extraordinario de AMFOLCHI, respondiendo a variados temas de interés para sus asociados, por ejemplo: políticas culturales del gobierno, relaciones y colaboración con las instituciones gubernamentales, situación orgánica de la asociación, revisión de algunos conceptos fundamentales sobre educación, proyección, comunicación, etcétera.

En tal contexto, destacó la exposición ofrecida por Fidel Sepúlveda Llanos, fallecido docente de la Pontificia Universidad Católica de Chile, quien, desde la poesía y la investigación, dejó una huella imborrable en el ámbito cultural chileno, realizando una valiosa labor de rescate, investigación y difusión de nuestro patrimonio cultural inmaterial. En su plática, el docente revitalizó el sentido de pertenencia a la organización y llamó a dotarla de una mirada nacional, es decir, que la institución extendiera su quehacer a todo el país. De este modo, se alcanzó el acuerdo de transformarla en la Asociación Nacional del Folklore de Chile - ANFOLCHI, acogiendo a los grupos regionales.

Fruto de esa transformación se incorporaron muchos socios y socias, integrantes de diferentes conjuntos folklóricos a lo largo del país. El libro de socios registra a 221 personas, aunque en la actualidad sólo se mantienen activas 49 , en todo el territorio nacional. Las razones de la actual disminución de sus integrantes tienen que ver con el fallecimiento de muchos de ellos, el cambio de otros hacia organizaciones distintas o por diversos factores personales.

Desde la década de 1990, ANFOLCHI ha entablado alianzas con organismos afines, como la Sociedad de Escritores de Chile, SIDARTE y el Centro Cultural Estación Mapocho. Con el tiempo, estos vínculos fueron cambiando y actualmente se mantienen con distintas oficinas de la Biblioteca Nacional de Chile, la Biblioteca de Santiago, el Museo de la Educación Gabriela Mistral y el Ministerio de las Culturas, las Artes y el Patrimonio, entre otros. De ese modo, la Asociación fue creciendo en el tiempo, en su capacidad de convocatoria, organización y trascendencia.

Teniendo como referente el Día Internacional del Folklore, fijado por UNESCO el 22 agosto de 1960, ANFOLCHI decidió dedicar este mes a las materias de nuestro interés. En ese marco, en la década de los 80, el Cardenal Raúl Silva Henríquez motivó a la directiva de entonces a celebrar anualmente una Misa de Acción de Gracias en la Basílica de Lourdes, tradición que se ha mantenido por casi cuarenta años, al igual que realizar allí presentaciones de Villancicos en Navidad. En la misma década, se fundó el Boletín Informativo 
de nuestra asociación, el que derivó con el tiempo en nuestra revista El Arado, cuya quincuagésima edición fue presentada en octubre de 2018.

Los y las asociadas de ANFOLCHI, son integrantes de variadas agrupaciones, la mayoría de larga data, muchas conocidas en el medio y con abundantes producciones discográficas. Entre otras, el Grupo Paillal, Conjunto Rhailén, Grupo Trehuaco, Conjunto Coyahue, Taller Columbé, Grupo Encore de Chile, Conjunto Rehue y Cantos de Chile.

\begin{abstract}
Al revisar la aparición del Decreto 23, en el número de El Arado correspondiente a abril de 2008, recién se hace referencia explícita de éste. Allí, don Juan González Gallegos señala que “[...] el reconocimiento, práctica y vigencia de la cueca, no se debe a un decreto ni a organizaciones especializadas. La cueca, tanto como otras manifestaciones, las mantiene el pueblo en forma natural y empírica, en diferentes variantes, formas y estilos, todos válidos. Esta danza tiene una estructura y coreografía básica además de pasos que la identifican, pero el sentimiento, la gracia, la vestimenta, la expresión, la comunicación, la ponen los que la bailan, sean jóvenes o ancianos, de Arica o Chile Chico [...]". Asimismo, “[...] ni reglamentos ni jurados le hacen favor a lo que el pueblo ha manifestado de manera vernácula. La cueca competitiva es maravillosa y muy hermosa visualmente y hay que aplaudir a los atletas ejecutores, pero no declaren que eso es parte de la cultura popular tradicional, o sea del folklore; esa cueca es una moda". Por último, el autor afirma que "[...] la cueca, como manifestación de cultura, no debe estancarse, pero el único que puede hacerle cambios es el pueblo, la tradición y no una organización [...] La cueca espontánea es parte del folklore; las de competencia sólo parte de un atractivo y llamativo show." ${ }^{\prime 1}$
\end{abstract}

Durante las celebraciones del bicentenario de la Independencia de Chile, como Asociación impulsamos una reflexión en torno a las implicancias sociohistóricas y críticas del Decreto № 23, derivadas asimismo de la convicción de que, históricamente, la construcción de los símbolos patrios se ha dado a espaldas de buena parte de las genuinas expresiones populares. Lo central de estos principios fueron precisamente descritos por Juan González en el citado artículo.

Como Asociación, consideramos que la promulgación del Decreto № 23 no tuvo presente los siguientes antecedentes y principios:

1. Históricamente, en nuestro país existían antiguas intérpretes reconocidas en el folklore, por ejemplo, Las Caracolitos, Las Hermanas Freire, Violeta e Hilda Parra, Los Cuatro Huasos, Hermanas Loyola, entre tantos más. Luego, 
con la aparición de los Conjuntos Cuncumén, Millaray, la Agrupación Folklórica de Raquel Barros en la década de 1950, se levantaron propuestas sobre la base de una rigurosa proyección folklórica, basada en la recopilación, investigación y difusión de cantos y danzas del mundo campesino.

2. Adicionalmente, con la creación de la Escuela Musical Vespertina, al amparo de la Universidad de Chile, en 1970, con el respaldo de la Decana de la Facultad de Música, la señora Elisa Gallán, se favoreció una formación estructurada en folklore: canto, danza, ejecución instrumental, interpretación, etcétera, lo que fortaleció el movimiento cultural en cuestión. Dicha Escuela gozó de buena acogida entre los grupos emergentes de la época.

3. Por otro lado, el Programa Arte para Todos (1970-1973), dirigido por la Universidad Técnica del Estado, también tuvo amplia difusión de actividades artístico-culturales -ballet, teatro, música, etc.- a nivel comunal y regional, lo que permitió desde el folklore mostrar la diversidad de expresiones de éste, que trascendían la cueca huasa, tan promocionada por el decreto en cuestión.

A fines de la década de 1970, en definitiva, existía un amplio movimiento de grupos e investigadores dedicados a los valores e importancia de la cultura popular, y cuyos temas de investigación iban mucho más allá de la cueca, y sobre cierta unanimidad respecto de la integralidad de aspectos que abarcaba la cultura popular. Esta enorme y rica diversidad fue suprimida por el Decreto № 23 pues la legislación terminó por favorecer a una sola expresión de la cultura tradicional -la cueca, sólo en su variante huasa-, supresión que afectó profundamente los conocimientos y experiencias particulares del ámbito folklórico nacional.

Es necesario insistir que, para ese amplio contingente de folkloristas, la cueca era sólo una más dentro de la totalidad de expresiones en la cultura musical y coreográfica de nuestro folklore. En consecuencia, el Decreto 23 no pudo anular lo reflexionado acerca de la importancia de una mirada integral sobre las manifestaciones folklóricas, y lo compartido durante los tiempos de formación como monitores, intérpretes y/o estudiosos del folklore.

Previamente a la firma del Decreto, quienes veníamos de la vieja escuela de la cultura tradicional, con experiencia investigativa, conocíamos distintas formas de cuecas, como expresión de sentimientos e identidad, acordes con las cosmovisiones locales y actividades productivas que las personas desarrollaban. Entre las variantes regionales o tópicas que hemos logrado investigar, se encuentran las cuecas de velorio, valseada, del angelito, cueca larga, del balance, brava, chora, porteña, de fiestas, de trilla, de novenas, de casamiento, 
campesinas, de mineros, de pescadores, costinas, cordilleranas, citadinas, cuecas camineras, cuecas carcelarias, etcétera. El pueblo supo moldear y mantener esta enorme variedad en sus ámbitos cotidianos y de sociabilidad, fuera del alcance de la cueca "huasa" que el Decreto 23 insistía en imponer.

Otro factor importante para la comprensión del lugar de ANFOLCHI en el proceso de "nacionalización" de la cueca, tiene que ver con el momento político que enmarca la redacción del Decreto. ${ }^{2}$ Es innegable que un buen número de grupos folklóricos o de sus integrantes observaban una posición política contraria a quienes lo promovieron desde el folklore, ya que no comulgaban con ese esfuerzo por "alinear" a la chilenidad.

Allí justamente radica la razón por la cual los grupos asociados a ANFOLCHI no asumieron este Decreto, optando, más bien, por continuar trabajando su proyección folklórica como la conocían y practicaban, histórica, social y académicamente. Ergo, respetaron los orígenes y la diversidad de las expresiones folklóricas, en vez de "innovar", a través de la cueca huasa, como una herramienta de "competencia" e "identidad". En síntesis, asociadas y asociados no se dejaron eclipsar por una cultura impuesta para construir símbolos nacionales que no les interpretaban.

Como Asociación Nacional del Folklore, asumimos que las manifestaciones folklóricas son un ente vivo, amplio y diverso, que da cuenta del origen rural de un importante número de ciudadanos de este país, quienes añoraron y nos heredaron su sentir por el campo -en el caso de descender de centrinos-, sus costumbres, las comidas, las artesanías, el lenguaje, la medicina popular, ritos, usos, mitos y leyendas, entre otros patrimonios.

En síntesis, el Decreto № 23 resultó reduccionista a ojos de la ANFOLCHI, pues no apeló a esas herencias familiares y biográficas, como el que no incluyera, como era debido, las otras expresiones de la tradición. Los terrenos del folklore y la cultura popular, también trascienden los límites políticos de lo nacional y, en este caso, la cueca -según las teorías de estudiosos y de literatos- exponen que en sus orígenes fue transculturizada del Perú -derivada de la zamba, con orígenes africanos y criollos, según Carlos Vega- y de origen arábico-andaluz -según Benjamín Vicuña Mackenna-. Por lo tanto, este Decreto, al "nacionalizarla", impuso un discurso que difiere de las influencias culturales de las poblaciones inmigrantes, parte fundamental de nuestros orígenes mestizos.

El tema ha sido tratado por Rojas, Araucaria Sotoconil (2009). "Las cuecas como representación estéticopolíticas de chilenidad en Santiago entre 1979 y 1989". Revista Musical Chilena LXIII, 212, pp. 51-76. 
ANFOLCHI, a través de sus representantes, junto con otras organizaciones de folklore, acusaron recibo de los efectos del Decreto y actuaron en consecuencia. Lo anterior quedó en evidencia durante el II Cuecazo Metropolitano, celebrado en octubre de 1995 en el Aula Magna de la Universidad de Santiago de Chile, organizado por la Agrupación Folklórica Metropolitana AFOM con la participación de nuestra agrupación. A partir de la experiencia adquirida con su primera versión, las nuevas bases del evento lo declararon "[...] encuentro no competitivo, excluyendo el uso de espuelas y corraleras en el varón". Dichas bases recogieron una serie de decisiones y conceptos reñidos con la versión de la cueca inculcada por el Decreto № 23, a saber: una definición de lo que se entendía por estilo urbano y campesino, referente especialmente al vestuario tradicional. Algunas de las razones esgrimidas en el documento aludían a que "[...] no correspondía a una forma o estilo propiamente de carácter folklórico", o a que "[...] estos son implementos de trabajo del huaso, no se han hecho para bailar ni forman parte de la vestimenta del hombre de campo."3

Durante la preparación del Cuecazo se realizó una mesa redonda titulada “La cueca ¿baile nacional?" que contó con la participación de Raquel Barros, Hiranio Chávez, Jorge Cáceres, Gabriela Pizarro y Gala Torres, entre otros expertos. Allí el debate se centró en la pregunta ¿cómo es posible reafirmar la identidad chilena frente a la avalancha de modelos culturales, sin incurrir en los excesos reduccionistas y formalistas incitados por el Decreto y su preferencia por la cueca huasa? ${ }^{4}$ Por ello resulta significativo que recién en abril de 2008, se mencione el Decreto № 23 en la revista El Arado, en un artículo titulado La cueca: encuentros y desencuentros.

A modo de síntesis, asumimos que las ramas del folklore, coreográfico, musical, demosófico y literario, representan la cosmovisión del patrimonio cultural, son aspectos que integran lo que ancestralmente nuestros pueblos han hecho parte de su existencia en el mundo, la visión del colectivo heredado, los valores y las formas traspasadas por generaciones, fortalecido por la profunda carga emocional que los sustentan. Con base en estos principios, y con relación al impacto particular del Decreto № 23 de 1979, en la institucionalidad que representamos, es posible afirmar que muchos de los elementos planteados acá, son compartidos entre nuestros y nuestras asociadas. Definitivamente, este Decreto no fue relevante para nuestra asociación, ni fue considerado un marco legal útil para el quehacer de los conjuntos folklóricos e intérpretes que formábamos parte de esta agrupación.

El Arado 22, "2 Gran Cuecazo Metropolitano - AFOM", diciembre 1995, pp. 37-38.

El Arado 22, “2 ${ }^{\circ}$ Gran Cuecazo Metropolitano... 
Es importante para ANFOLCHI terminar esta presentación con las palabras de Fidel Sepúlveda Llanos, quien en la década de 1991 señaló que: “[...] no es posible avanzar en un desarrollo realmente humano, sin una atención efectiva a la cultura [...] ni es posible sin una disponibilidad de las instancias de poder, para auscultar el sentir, la visión de mundo de las bases locales, regionales, rurales, urbanas, indígenas, mestizas, nacionales, continentales." 5

El Arado 20, Sepúlveda Llanos, Fidel “Identidad cultural”, (julio 1991), pp. 20-28. 
